\title{
Control of Chemical Reaction of Aluminium Nanoparticles by Silicon Polymer Coating
}

\author{
Toshiyasu Nishimura* \\ National Institute for Materials Science (NIMS), 1-2-1 Sengen, Tsukuba, Japan
}

\begin{abstract}
By using silicon polymer, the chemical reaction of Aluminium nanoparticles was controlled, especially, the corrosion reaction was reduced. The coverage of the silicon polymer film on Al nanoparticles was controlled, which changed the chemical reaction rate quantitatively. TEM (Transmission Electron Microscope) analysis indicated that the polymer film of $10 \mathrm{~nm}$ thick fully covered Al nanoparticle in the case of 5 mass\% polymer coated Al particles in the synthesis. On the other hand, 0.4-1.0 mass \% polymer coated Al was partially covered by a film. The AFM-KFM (Atomic Force Microscope-Kelvin prove Force Microscope) demonstrated that the conductivity of the Al nanoparticle was isolated by the polymer. Both the corrosion and $\mathrm{H}_{2}$ evolution reaction rates were quantitatively reduced by the mass $\%$ of polymer coating on the surface of Al particle. This fact suggested that the electrochemical reaction was suppressed by the polymer coating. It was found that the chemical reaction rate of Al nanoparticles could be quantitatively controlled by the coverage of the silicon coating.
\end{abstract}

Keywords: Polymer; Nanoparticle; Chemical reaction; Aluminium

\section{Introduction}

The nano materials are characterized as a small particle or a tube having at least one side with a length in the nano meter range. Thus, the surface area of nano materials is increased remarkably, enabling them to have dramatically increased surface reaction rates. The size effect of nano materials to increase the reaction rate has been investigated in the fields of catalysis [1-5], sensors [6-8] and batteries $[9,10]$.

As the reaction rate is increased by making the particle nano-sized, then, the deterioration of nano metal should be caused by the corrosion under the atmosphere at high humidity. Moreover, in the case of coastal area, the air bone salt particles are coming from the sea, which make the sever corrosion condition. On the other hand, the film thickness of coating should be very thin because each nanoparticle needs to be coated separately without bonding each other in the synthesis. Thus the coating technique should be very high level. Although it is necessary to prevent the corrosion of metal nano particles, there are few papers on this problem. Several papers show the effect of nanoparticles on the corrosion of the matrix of metals, coatings and composites. However, there very few paper which investigates the corrosion of nanoparticle itself.

In this paper, the control the chemical reaction of $\mathrm{Al}$ nanoparticles was tried by using a silicon polymer coating. The chemical reaction of these nano $\mathrm{Al}$ was changed by control the coverage of the polymer coating quantitatively. The polymer film on $\mathrm{Al}$ was observed by using TEM and AFM in detail. Besides, the corrosion reaction was examined for coated nano $\mathrm{Al}$ by the wet and dry test using a $\mathrm{NaCl}$ solution. Moreover, $\mathrm{H}_{2}$ evolution reaction rates were quantitatively examined by changing the mass $\%$ of polymer coating. Then, the relationship between the mass\% of polymer coating and the reaction rate of the nano metal was discussed. Finally, the chemical reaction reducing mechanism was discussed by changing the coverage of the polymer on nano $\mathrm{Al}$ quantitatively.

\section{Experimental}

\section{Materials and synthesis}

The $\mathrm{Al}$ nanoparticles were made by using the atomizing method. $\mathrm{Al}$ was melted and dropped through the tandewish, then, atomized in high-pressure water. The size of Al particles were around 300-600 nano meters $(\mathrm{nm})$ in diameter. In order to improve the surface activity, $\mathrm{Al}$ surface oxide was completely removed in an acidic solution. Moreover, this process was recognized very important in conducting the synthesis of the polymer only on the metal nanoparticles.

Figure 1 indicates the chemical reaction for the synthesis of silicon polymer on the $\mathrm{Al}$ nanoparticle. The silicon polymer was dissolved in an ethanol solution with the Al nanoparticles. After the ethanol was completely evaporated in the vacuum, the silicon polymer was hardened. Thus, the polymer was completely consumed to make the thin film on the nanoparticles. The mass $\%$ ratios of the polymer to $\mathrm{Al}$ particle in the synthesis were $0,0.4,1.0,3.0$, and $5.0 \%$, where the coverage of polymer film on the surface of the nanoparticle was changed quantitatively.

\section{Surface analysis for coated Al nanoparticles}

To investigate the chemical state of the polymer film in detail, Electron Energy Loss Spectroscopy (EELS) spectra were observed by TEM with the accelerated voltage of $200 \mathrm{kV}$. Three windows method was used to detect the each peak in this study. Moreover, to investigate the electrochemical reaction, the nano level measurement on the sample was applied by AFM and KFM. Firstly, the ultra-sonication was conducted at $23 \mathrm{kHz}$ for $20 \mathrm{~min}$. in $99.5 \%$ ethanol at $30^{\circ} \mathrm{C}$ where nanoparticles were separated each other. Then, particles were set on a polished Pt plate, then, AFM and KFM measurements were conducted. The surface morphology (AFM) and potential distribution (KFM) measurements were conducted simultaneously by tapping mode using gold coated cantilevers with a spring constant of $2.1 \mathrm{~N} / \mathrm{m}$.

*Corresponding author: Toshiyasu Nishimura, National Institute for Materials Science (NIMS), 1-2-1 Sengen, Tsukuba, Japan, Tel: 81298592127; E-mail: NISHIMURA.Toshiyasu@nims.go.jp

Received June 06, 2017; Accepted June 13, 2017; Published June 14, 2017

Citation: Nishimura T (2017) Control of Chemical Reaction of Aluminium Nanoparticles by Silicon Polymer Coating. J Adv Chem Eng 7: 173. doi: 10.4172/2090-4568.1000173

Copyright: (c) 2017 Nishimura T, et al. This is an open-access article distributed under the terms of the Creative Commons Attribution License, which permits unrestricted use, distribution, and reproduction in any medium, provided the original author and source are credited. 


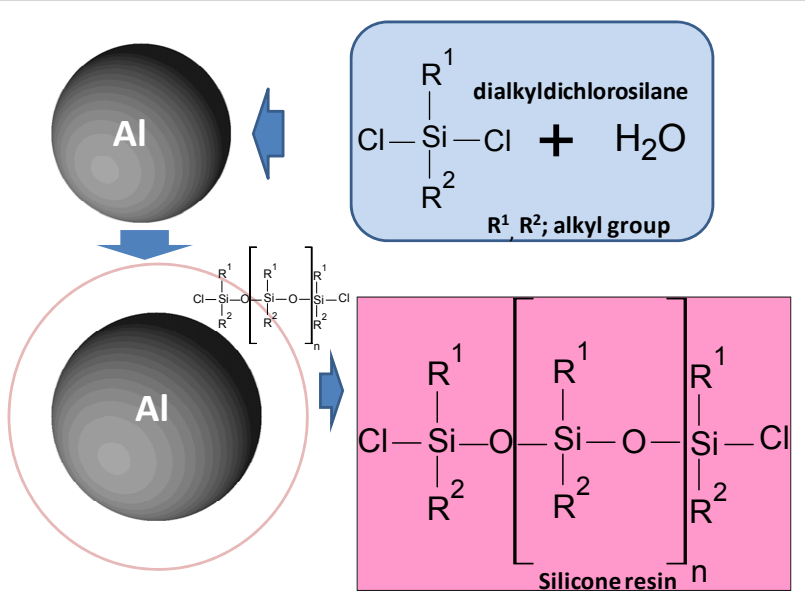

Figure 1: Schematic diagram of the chemical reaction for synthesis of the silicon polymer coated on Al nanoparticles.

\section{Chemical reaction tests}

In order to estimate the corrosion rate of the polymer coated $\mathrm{Al}$ nanoparticles, wet and dry corrosion tests were applied in a 0.5 mass $\%$ $\mathrm{NaCl}$ solution for 14 days (cycles). Only for the first cycle of testing, a 0.5 mass $\% \mathrm{NaCl}$ solution was dropped on the $\mathrm{Al}$ nanoparticles over the platinum (Pt) plate in a chamber kept at $40 \%$ relative humidity $(\mathrm{RH})$ and $25^{\circ} \mathrm{C}$. Under this condition, the sample was kept and dried for several hours. From the 2nd cycle of the test, pure water was poured on the samples under the same conditions in every $24 \mathrm{hrs}$. As the $\mathrm{NaCl}$ remains on the Pt plate, corrosive conditions have maintained after the $2^{\text {nd }}$ cycle of the test. After the corrosion test, the corrosion behaviour of the nanoparticles was observed by SEM. Especially, it was investigated that the corrosion rate was suppressed in proportion to the mass $\%$ of the polymer coating.

In the same way, the effect of coating mass $\%$ on the volume of the hydrogen $\left(\mathrm{H}_{2}\right)$ evolution reaction on Al nanoparticles was examined. The volume of $\mathrm{H}_{2}$ evolution reaction for $70 \mathrm{mg}$ of $\mathrm{Al}$ nanoparticles was measured in a $0.5 \mathrm{M} \mathrm{NaOH}$ solution. The evolving $\mathrm{H}_{2}$ gas was taken into the glass filled with the solution, and the volume was measured by the mess cylinder. Finally, the effect of the mass $\%$ of polymer coating on the chemical reaction for the nano $\mathrm{Al}$ was discussed in Figure 1.

\section{Results and Discussion}

\section{Characterization of coated $\mathrm{Al}$ nanoparticles}

SEM images of (1) 0.4 mass $\%$ and (2) 5 mass $\%$ polymer coated $\mathrm{Al}$ nanoparticles are shown in Figure 2. Here, 5 mass\% means that the weight ratio of polymer is 5 mass\% against that of $\mathrm{Al}$ particle. The particle diameter is indicated $300-500 \mathrm{~nm}$ in the figure. The particle of 0.4 mass \% coated $\mathrm{Al}$ is partially covered by the silicon polymer. On the other hand, in the case of 5 mass $\%$ coated $\mathrm{Al}$; the particle is covered fully by the polymer.

The actual mass\% of polymer to $\mathrm{Al}$ nanoparticles was measured by the thermo-gravimetric (TG) analysis under an $\mathrm{N}_{2}$ atmosphere (Figure 3 ). When the temperature was above 200 degree $C$, the weight of the nanoparticle decreased due to the epoxy decomposition by melting or evaporation. The weight loss of the $0.4,1,3$, and 5 mass $\%$ coated $\mathrm{Al}$ nanoparticle was $0.5,0.8,1.8$, and 3.2 mass $\%$, respectively, as measured by TG. The weight loss in TG is shown almost the same as the mass\% in the synthesis. Thus, the synthesized polymer is kept on the surface of $\mathrm{Al}$ nanoparticle. The mass\% of actual polymer coating to $\mathrm{Al}$ can be controlled by using the mass $\%$ of polymer in the synthesis (Figures 2 and 3).

The TEM images are shown in Figure 4 to investigate the coating film of the epoxy polymer in detail. The $10 \mathrm{~nm}$ thick polymer coats uniformly the entire surface of 5 mass\% coated $\mathrm{Al}$ nanoparticles. Thus, it is thought that the amount of 5 mass\% polymers is enough to cover all surface of Al nanoparticle Figure 4.

The chemical elements in the polymer of 5 mass\% coated $\mathrm{Al}$ was estimated by the EDS (Electron Dispersive Spectroscopy) spectrum in Figure 5. The elements of $\mathrm{Al}, \mathrm{Si}, \mathrm{O}$ and $\mathrm{C}$ were detected with the $\mathrm{Cu}$ from the mesh. In order to estimate the chemical state of $\mathrm{Al}, \mathrm{Si}, \mathrm{C}, \mathrm{O}$, the EELS spectra were obtained for the polymer film of 5 mass $\%$ coated $\mathrm{Al}$ in Figure 6. In the case of Al-L spectrum, a sharp peak is shown at $80 \mathrm{eV}$, which is similar to that of $\mathrm{Al}_{2} \mathrm{O}_{3}$. On the other hand, $\mathrm{Al}-\mathrm{L}$ spectrum has a shoulder around $75 \mathrm{eV}$, moreover, $\mathrm{Al}-\mathrm{K}$ spectrum has a little broad style. Thus, the state of $\mathrm{Al}$ is not exactly $\mathrm{Al}_{2} \mathrm{O}_{3}$, but the oxidized state. In the case of $\mathrm{Si}-\mathrm{L}$ spectrum, a sharp peak is indicated at $110 \mathrm{eV}$, besides, a sharp peak is shown at $1870 \mathrm{eV}$ in Si-K, which is similar to that of $\mathrm{SiO}_{2}$. Besides, a strong peak is indicated at $540 \mathrm{eV}$ in $\mathrm{O}-\mathrm{K}$ spectrum, and a broad peak at $565 \mathrm{eV}$, which shows that the polymer is the oxidized state. The state of $\mathrm{Si}$ is thought an oxidized one similar to $\mathrm{SiO}_{2}$. This result corresponds to the reaction of synthesis of the silicon polymer in Figure 1. A strong peak is shown at $284 \mathrm{eV}$ in C-K EELS spectrum, which is thought to reflect $\left(1 \mathrm{~s} \rightarrow \pi^{*}\right)$ transition. Besides, a broad peak is observed at $290-300 \mathrm{eV}$, which is thought to reflect $\left(1 \mathrm{~s} \rightarrow \mathrm{o}^{*}\right)$ transition. Figure 7 indicates EELS mappings of elements for 5 mass $\%$ coated Al, where (a) Al-L, (b) C-K, (c) Si-L and (d) O-K. The polymer film on Al particle has the high concentration of $\mathrm{O}$. However, the concentration of $\mathrm{Al}$ is very low on the particle due to the high thickness of $\mathrm{Al}$ particle. On the other hand, the concentration of $\mathrm{Si}$ is high on the particle, which is caused from the thin polymer film. Thus, the high concentration of O-K in the film is thought to reflect the chemical bond of silicon polymer. Thus, the chemical state of the silicon polymer film was shown by the EELS measurement.

\section{Effect of coating film on the chemical reaction}

Figure 8 indicates AFM and KFM (potential distribution) results conducted by the tapping mode. The 0 mass $\%$ (uncoated) Al particle represents a half globe in KFM image, which is almost the same as the AFM one. The 1.0 and 3 mass\% coated $\mathrm{Al}$ particle display broken shapes in KFM images, which is different from half globe shapes in AFM. Therefore, in the case of 1.0 and 3 mass $\%$ coated $\mathrm{Al}$; the potential around the $\mathrm{Al}$ particles is partially isolated from the Pt plate by the polymer coating. Thus the coverage of the polymer suppresses the electrochemical reaction. In other word, the corrosion reaction of metal particle can be suppressed by the coverage of the polymer film (Figure 8).

The effect of coating mass $\%$ on the volume of the hydrogen $\left(\mathrm{H}_{2}\right)$ evolution reaction on $\mathrm{Al}$ nanoparticles is shown in Figure 9. The evolution volume $\left(\mathrm{V} \mathrm{H}_{2}\right)$ of $\mathrm{H}_{2}$ for $\mathrm{Al}$ of $70 \mathrm{mg}$ nanoparticles was evaluated in a $0.5 \mathrm{M} \mathrm{NaOH}$ solution. From the Figure, the $\mathrm{V} \mathrm{H}_{2}$ for each sample increases according to the test time. After $300 \mathrm{~s}$, the 0 , $0.4,1.0,3.0$ and 5 mass\% coated $\mathrm{Al}$ has $\mathrm{V} \mathrm{H}_{2}$ of $14,9,4.5$ and 0.2 and $0 \mathrm{~mL}$, respectively. Thus, $\mathrm{V} \mathrm{H}_{2}$ is less as the coating mass\% increases. Therefore, the $\mathrm{H}_{2}$ evolution reaction was suppressed in proportion to the mass\% of polymer coating (Figure 9). In order to estimate the effect of coating film on the chemical reaction, a wet and dry corrosion test with a $\mathrm{NaCl}$ solution was performed. The $\mathrm{Al}$ nanoparticles was put into a 0.5 mass $\% ~ \mathrm{NaCl}$ solution on Pt plate in a chamber at $40 \%$ Relative 

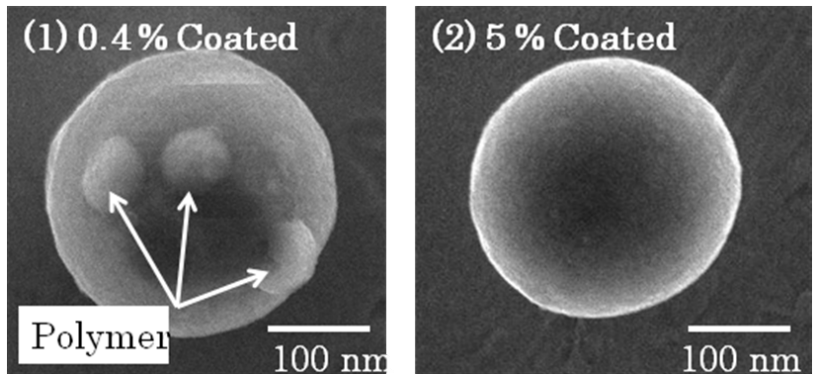

Figure 2: SEM image of (1) 0.4 mass $\%$ and (2) 5 mass $\%$ polymer coated Al nanoparticles.

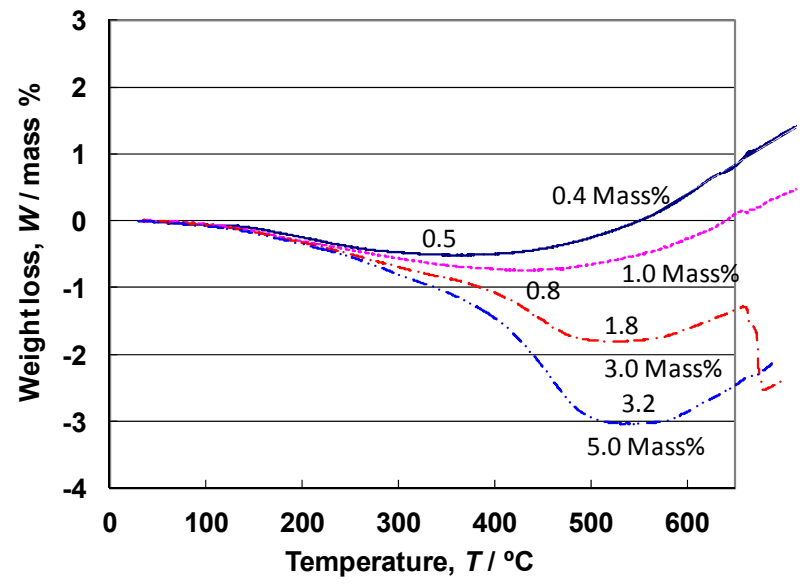

Figure 3: Thermo Gravimetric (TG) analysis for the silicon coated Al nanoparticles.

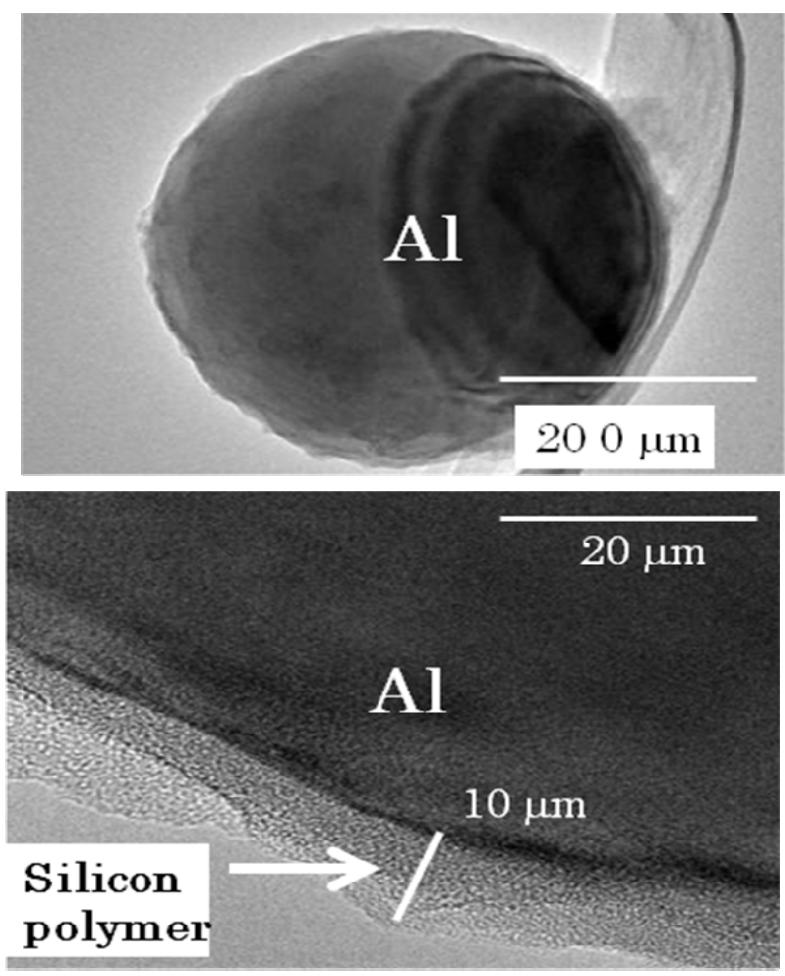

Figure 4: TEM images of 5 mass $\%$ silicon coated Al nanoparticles.

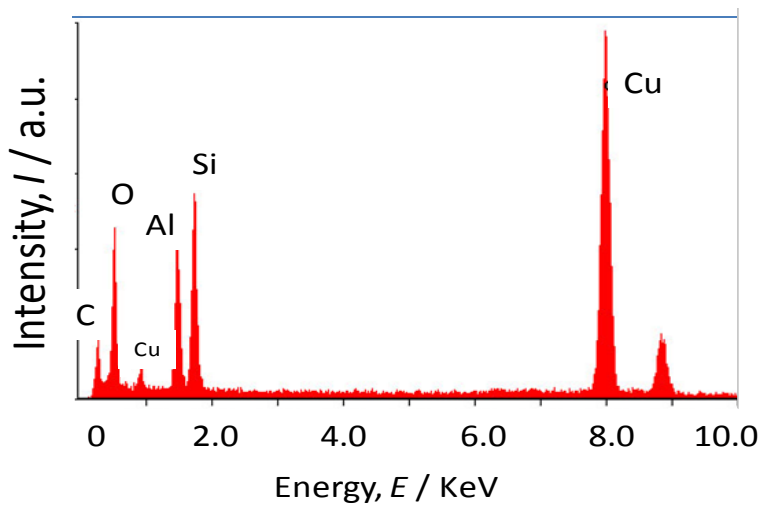

Figure 5: EDS result of the surface on 5 mass $\%$ silicon coated Al nanoparticles.
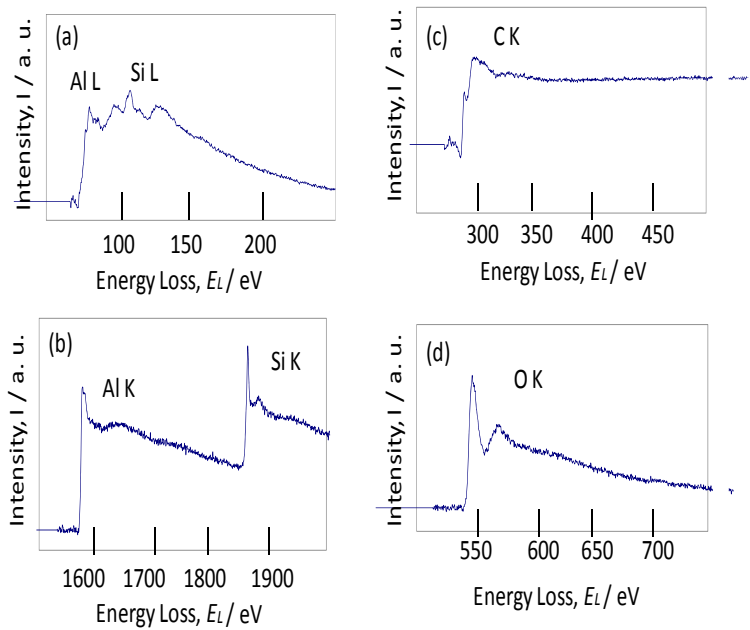

Figure 6: EELS spectra of (a) Al-L, Si-L, (b) Al-K, Si-K, (c) C-K and (d) O-K for 5 mass $\%$ polymer films on coated $\mathrm{Al}$


Figure 7: EELS mapping for 5 mass $\%$ polymer films on coated Al. (a) Al-L, (b) C-K, (c) Si-L and O-K. 




Figure 8: AFM and KFM images for (1) $0 \%$, (2) $3 \%$ and (3) $5 \%$ silicon coated Al nanoparticles.

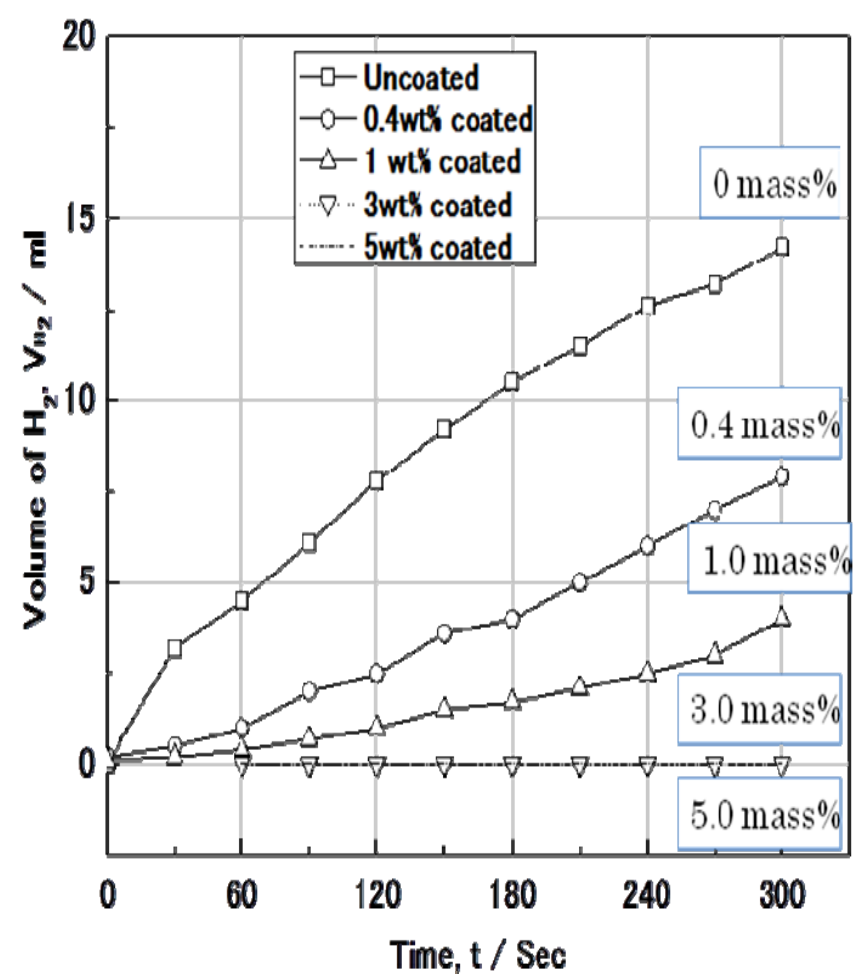

Figure 9: Effect of coating mass $\%$ on the hydrogen $\left(\mathrm{H}_{2}\right)$ evolution reaction on Al nanoparticles.

Humidity (RH) and $25^{\circ} \mathrm{C}$. SEM images of the $\mathrm{Al}$ nanoparticles after the corrosion test at each day are indicated in Figure 10. The shape of the 3 mass\% polymer coated sample keeps the initial one after 14 days, showing that it is not subjected to the corrosion. This corrosion prevention is caused by the coverage of polymer which isolates $\mathrm{Al}$ particles from the Pt plate. On the other hand, the shape of 0 mass\% (uncoated) samples is partially changed at 7 days, and continues to be corroded, yielding to a slender-shape at 14 days. The corrosion is thought to start from the bare (no polymer) position of a metal and the electrochemical reaction keeps in that region. Finally the galvanic corrosion between Al particle and Pt plate is thought conducted for 14 days. Thus, the $\mathrm{Al}$ nanoparticle changes in the shape according to the polymer coating mass $\%$ after the corrosion test (Figure 10).

The effect of the coating mass\% on the sizes of the $\mathrm{Al}$ nanoparticles after a wet and dry $\mathrm{NaCl}$ corrosion test was estimated in Figure 11. The size of the $\mathrm{Al}$ nanoparticles was normalized by the supposition that the initial diameter for particles was $100 \%$. The initial sizes of diameters (D) were measured for 20 particles in SEM, where the volume (V1) was calculated as $(4 / 3)(\mathrm{D} / 2)^{3}$. After the corrosion test, the long $(\mathrm{L})$ and short (S) diameters were measured, where the volume (V2) was $(4 / 3)$ $(\mathrm{L} / 2)(\mathrm{S} / 2)^{2}$.

The normalized size (SN) is identified as following:

$\mathrm{SN}=($ average size of $\mathrm{V} 2$ for 20 particles)/(average size of $\mathrm{V} 1$ for 20 particles)

The normalized size (SN) of 0 mass\% (uncoated) $\mathrm{Al}$ decreases remarkably with time in the corrosion test, showing that the corrosion rate is very high. However, the $\mathrm{SN}$ of the 3 mass \% coated $\mathrm{Al}$ is hardly changed. Thus, the corrosion is thought prevented by the polymer film in the case of 3 mass $\%$ coated Al. After 14 days, the SN of the 0, 0.4, 1.0 and 3 mass $\%$ coated samples are $80,85,91$, and $97 \%$, respectively. Therefore, the SN after 14 days shows higher value as the coating mass\% increases (Figure 11).

The effect of the polymer coating mass $\%$ on the reaction rate of $\mathrm{Al}$ nanoparticles in the corrosion and hydrogen $\left(\mathrm{H}_{2}\right)$ evolution test are summarized in Figure 12. The corrosion rate for each coated sample was calculated using the supposition that the amount of corrosion of 0 mass $\% \mathrm{Al}$ at 14 days was $100 \%$.

The rate (RC) of corrosion (C) for each coated sample at 14 days was calculated as:

$$
\mathrm{RC}(\%)=(\mathrm{C} \text { of each mass } \% \text { coated } \mathrm{Al}) \times 100 /(\mathrm{C} \text { of } 0 \text { mass } \% \mathrm{Al})
$$

In the same way, the rate of the $\mathrm{H}_{2}$ reaction was determined by the supposition that the volume of 0 mass $\% \mathrm{Al}$ at $300 \mathrm{~s}$ was $100 \%$. It is shown from the Figure that both rates are reduced as mass $\%$ of polymer coating increased. This fact indicates that electrochemical reactions on the Al particles under these conditions are suppressed by the polymer coating. Moreover, a quantitative relationship between the reaction rate and mass $\%$ of coating was established.

The reaction rate of $\mathrm{Al}$ nanoparticles was able to be quantitatively changed by the mass $\%$ of polymer coating. Besides, the mass $\%$ of actual polymer coating on a metal can be controlled by the mass $\%$ of polymer against that of $\mathrm{Al}$ in the synthesis. Therefore, the reaction rate can be controlled by the synthesis using the change of mass\% of polymer. In this way, the synthesis is able established using only the mass\% ratio of polymer to metal in the synthesis. Finally, it can be said that the chemical reaction of nano metals can be controlled by the silicon polymer coating (Figure 12).

\section{Conclusions}

The silicon polymer coating was conducted to control the chemical reaction of $\mathrm{Al}$ nanoparticle. The 5 mass $\%$ polymers coated $\mathrm{Al}$ particles in the synthesis were observed by TEM to be fully covered by a polymer film of $10 \mathrm{~nm}$ thick. The $0.4-1.0$ mass $\%$ coated $\mathrm{Al}$ was partially covered by a film. The potential around the Al particles showed a lower value by polymer coating in AFM-KFM, indicating that the conductivity of the nano $\mathrm{Al}$ was isolated by the silicon polymer. As the mass $\%$ of polymer coating increased, the reaction rates for both the corrosion and $\mathrm{H}_{2}$ evolution tests were reduced. Therefore, the chemical reaction on the Al particles was quantitatively suppressed by the polymer coating. 
Citation: Nishimura T (2017) Control of Chemical Reaction of Aluminium Nanoparticles by Silicon Polymer Coating. J Adv Chem Eng 7: 173. doi: 10.4172/2090-4568.1000173

Page 5 of 5

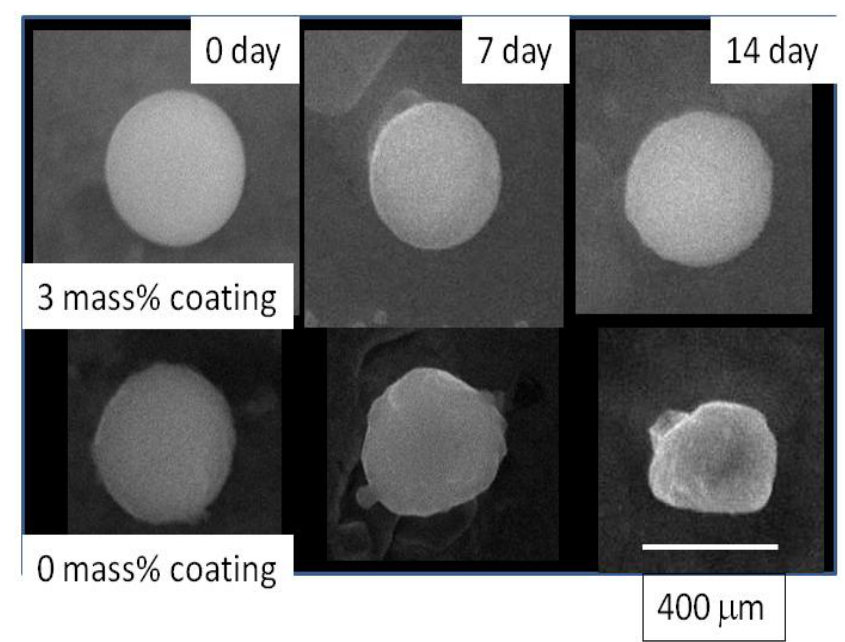

Figure 10: SEM images of (a) $5 \%$ and (b) $0 \%$ coated Al nanoparticles subjected to a wet and dry corrosion test for 0,7 and 14 days.

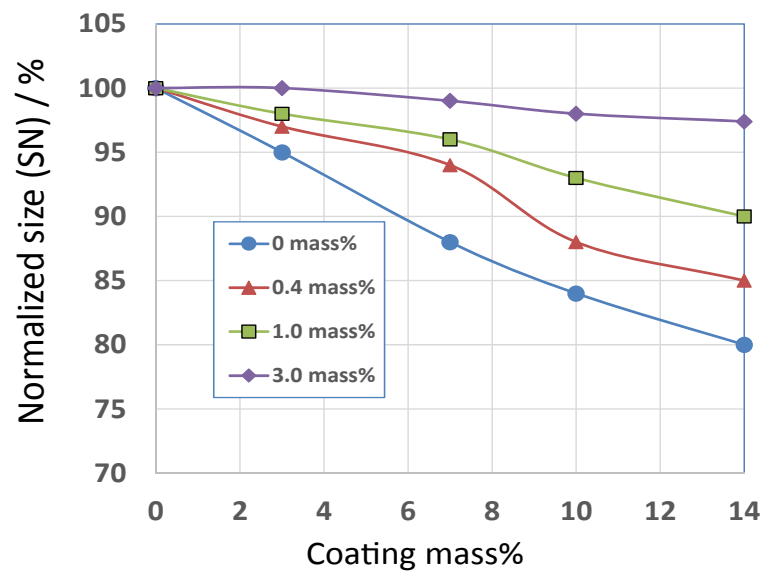

Figure 11: Effect of the polymer coating mass $\%$ on the normalized size (SN) of Al nanoparticles caused by the wet and dry corrosion test with $\mathrm{NaCl}$.

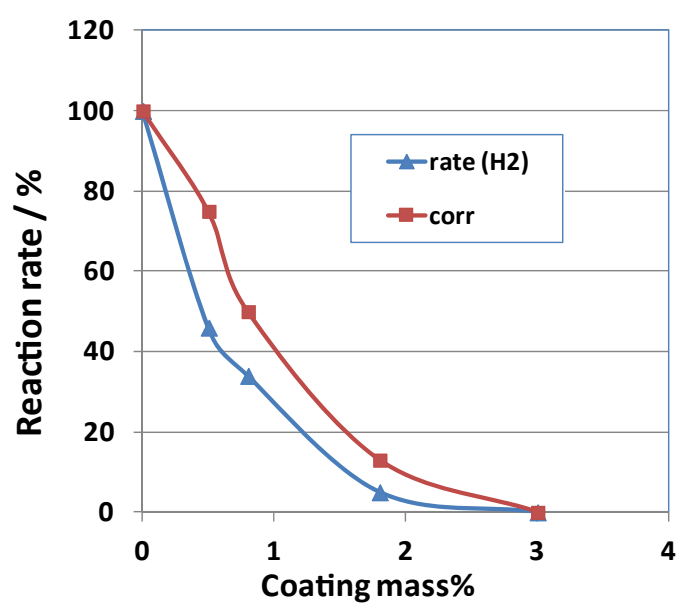

Figure 12: Effect of the polymer coating mass $\%$ on the reaction rate of $\mathrm{Al}$ nanoparticles in the corrosion and hydrogen $\left(\mathrm{H}_{2}\right)$ evolution test.
Thus, the chemical reaction rate of a nano metal could be controlled by a polymer coating in the synthesis.

\section{References}

1. Bond GC (1985) The origins of particle size effects in heterogeneous catalysis. Surf Sci 156: 966-981.

2. Sachtler WMH (1986) Morphology and crystal face specificity of catalysis on small particles. Ultramicroscopy 20: 135-143.

3. Haruta M (1997) Size- and support-dependency in the catalysis of gold. Catal Today, pp: 153-166.

4. Okumura M, Tanaka K, Ueda A, Haruta M (1997) The reactivities of dimethylgold(III) $\beta$-diketone on the surface of $\mathrm{TiO} 2 \mathrm{~A}$ novel preparation method for Au catalysts. Solid State lonics 95: 143-149.

5. Chan KY, Ding J, Ren J, Cheng S, Tsang KY (2004) Supported mixed meta nanoparticles as electro catalysts in low temperature fuel cells. J Matter Chem 14: 505-516.

6. Shimizu Y, Egashira M (1999) Basic aspects and challenges of semiconductor gas sensors. MRS Bulletin, pp: 18-24.

7. Tamaki J (1994) Grain-size effects in tungsten oxide-based sensor for nitrogen oxides. J Electrochem Soc 141: 2207-2210.

8. Gurlo A (1997) Grain size control in nanocrystalline $\ln _{2} \mathrm{O}_{3}$ semiconductor gas sensors. Sensors and Actuators B 44: 327-333.

9. Fujimoto $\mathrm{H}$ (1994) Effect of crystallite size on the chemical compositions of the stage 1 alkali metal-graphite intercalation compounds. Carbon 32: 193-198.

10. Tokumitsu K (1996) Electro chemical insertion of lithium into carbon synthesized from condensed aromatics. J Electrochem Soc 143: 2235-2239. 